\title{
FIRMEZA DE CAQUI 'GIOMBO' SUBMETIDO À APLICAÇÃO PÓS-COLHEITA DE CLORETO DE CÁLCIO ${ }^{1}$
}

\author{
MARIA ROSA DE MORAES ${ }^{2}$, ROGÉRIO LOPES VIEITES ${ }^{3}$, ÉRICA REGINA DAIUTO ${ }^{4}$, \\ NAGELA FARIAS MAGAVE PICANÇO ${ }^{5}$
}

RESUMO - Este trabalho teve por objetivo avaliar o efeito da aplicação pós-colheita do cloreto de cálcio na firmeza de caquis 'Giombo', destanizados ou não. Os frutos foram colhidos manualmente com aproximadamente $50 \%$ da coloração verde, transportados para o Laboratório, onde foram selecionados, higienizados e imersos em água (T1= controle), e em solução de cloreto de cálcio, por 10 minutos, nas seguintes concentrações: $\mathrm{T} 2=0,5 \% \mathrm{CaCl}_{2} ; \mathrm{T} 3=1,0 \% \mathrm{CaCl}_{2}$; $\mathrm{T} 4=2,0 \% \mathrm{CaCl}_{2}$; e T5 $=3,0 \% \mathrm{CaCl}_{2}$. Em seguida, foram acondicionados em bandejas de poliestireno expandido, revestidas por filme plástico de polietileno de baixa densidade (PEBD). O armazenamento foi a $0{ }^{\circ} \mathrm{C}$ e $85-90 \%$ UR, por 35 dias, com análise a cada 7 dias quanto à perda de massa, firmeza e atividade das enzimas poligalacturonase (PG) e pectinametilesterase (PME). Os frutos da testemunha do caqui não destanizado apresentaram, em média, a menor perda de massa e a maior manutenção da firmeza. Os frutos submetidos às diferentes concentrações de cálcio apresentaram as maiores atividades de PME no final do período de avaliação, sem diferença entre os tratamentos. Frutos não destanizados apresentaram menores atividades de PG quando comparados aos destanizados. A aplicação do cloreto de cálcio não apresentou incremento positivo na manutenção da qualidade e da firmeza dos caquis 'Giombo' . Termos para indexação: Diospyrus kaki ., destanização, poligalacturonase e pectinametilesterase.

\section{FIRMNESS OF 'GIOMBO' PERSIMMON SUBMITTED TO THE POSTHARVEST APPLICATION OF CALCIUM CHLORIDE}

\begin{abstract}
The effect postharvest application of calcium chloride was evaluated about the firmness of 'Giombo' persimmon. The fruits were harvest manually with the fruit ripe middle and with approximately $50 \%$ of the green coloration. The fruits without adstringency and adstringent were immersed in water (T1 $=$ it controls), and in solution of calcium chloride for 10 minutes. The evaluated concentrations were: T2 $=0.5 \% \mathrm{CaCl} 2, \mathrm{~T} 3=1.0 \% \mathrm{CaCl} 2, \mathrm{~T} 4=2.0 \% \mathrm{CaCl} 2$ and $\mathrm{T} 5=3.0 \% \mathrm{CaCl}_{2}$. The fruits were packed in expanded polystyrene (EPS) trays, covered by low densidy polyethylene (LDPE) and stored under refrigeration to the $0^{\circ} \mathrm{C}(85-90 \% \mathrm{UR} \%)$. It was evaluated the weight loss, firmness, polygalacturonase (PG) and pectinametylesterase (PME) enzymes activity. The persimmon control fruits with adstingency, presented, on average, to smallest weigth loss and the largest firmness The fruits submitted to the concentrations of calcium presented the largest PME activities in the end of the evaluations without difference among the treatments. Fruits with adstingency showed smaller PG activities of PG when compared to without adstingency. Calcium chloride application didn't showed positive increment in the quality maintenance of the firmness 'Giombo' persimmon.
\end{abstract}

Index terms: Diospyrus kaki L., adstringency, polygalacturonase, pectinametylesterase

\footnotetext{
${ }^{1}$ Trabalho Sinfruit 088 - Simpósio Internacional de Fruticultura - Avanços na Fruticultura (17 a 21 Outubro) 'Projeto Financiado pela FAPESP e CNPQ;

${ }^{2}$ Mestranda FCA/UNESP-Botucatu- Bolsista FAPESP. E-mail: mrmoraes@fca.unesp.br

${ }^{3}$ Prof. Titular, docente do Departamento de Gestão e Tecnologia Agroindustrial da Faculdade de Ciências Agronômicas da UNESP-Botucatu. E-mail: vieites@fca.unesp.br

${ }^{4}$ Pós doutoranda no Curso Horticultura FCA/UNESP-Botucatu. E-mail: erdaiuto@uol.com.br

${ }^{5}$ Doutora pelo curso Energia na Agricultura da FCA/UNESP-Botucatu
} 


\section{INTRODUÇÃO}

O caqui apresenta particularidades que garantem sua boa aceitação no mercado (SIMÃO, 1998) e dentre elas podem-se citar o excelente sabor, a aparência atraente e a elevada qualidade nutricional, pois é boa fonte de fibras, carboidratos (VASCONCELOS, 2000), vitaminas e sais minerais (WRIGHT; KADER, 1997), além do fato de a cultura deste fruto apresentar extraordinária adaptação às condições edafoclimáticas brasileiras (PENTEADO, 1986). No entanto, sua colheita é concentrada em três meses do ano, sendo que este fato e a falta de informações consistentes de como armazenar e transportar os frutos, tornam-se fatores limitantes da expansão da cultura, acarretando perdas no final do processo produtivo bem como durante a comercialização do fruto (DONAZZOLO; BRACKMANN, 2002).

Campo-Dall'Orto et al. (1996) classificam o caqui 'Giombo' como pertencente ao grupo denominado "variável", que inclui frutos de polpa taninosa e de cor amarelada, quando sem sementes, e não taninosa, parcial ou totalmente, quando com uma ou mais sementes. Na ausência de sementes, os frutos preservam a adstringência mesmo quando amadurecidos, necessitando de um processo artificial para a remoção da adstringência. Este processo é denominado destanização. O maior inconveniente de se acelerar o processo de amadurecimento, para promover a destanização dos frutos, é a diminuição da vida de prateleira do produto (EDAGI;KLUGE, 2009). Geralmente, os frutos de caqui 'Giombo' são expostos ao vapor do álcool etílico, que é um método prático de destanização, mas segundo Antoniolli et al. (2000) o processo pode comprometer a firmeza da polpa, quando armazenado por períodos prolongados. A utilização de práticas que atrasem a colheita dos frutos e prolonguem o armazenamento, pode ser uma alternativa para aumentar a rentabilidade da cultura. Dentre estas práticas, pode-se citar a utilização de armazenamento refrigerado, que mantém a qualidade dos mesmos por curto espaço de tempo (CHITARRA; CHITARRA, 2005). Outras técnicas propostas para o caqui, se aliadas ao armazenamento sob baixa temperatura, podem ser benéficas, como a utilização da atmosfera controlada (VIDRIH et al., 1990), o uso de cera (BLUM et al., 2008), a aplicação pós-colheita de 1-MCP (BRACKMANN et al. ,2003) e na pré-colheita de ácido giberélico (DANIELE et al., 2002).

As pulverizações com cálcio, durante as fases de pré-floração, floração e crescimento das frutas, têm sido recomendadas como forma de reduzir os índices de abortamento floral, os distúrbios fisioló- gicos pós-colheita, a taxa respiratória, a produção de etileno e de preservar a firmeza da polpa (PEREZ et al.,1995). O cálcio apresenta a capacidade de retardar os processos de amadurecimento e senescência das frutas (SCALON et al.,1996), ao diminuir a taxa respiratória e a produção de etileno, controlar distúrbios fisiológicos, manter a integridade e a funcionalidade das membranas celulares, além de manter a firmeza da fruta ao formar ligações entre pectinas ácidas da parede celular e lamela média (POOVAIAH, 1986; GLENN et al., 1988).

O objetivo deste trabalho foi avaliar o efeito do cálcio aplicado em pós-colheita, em caquis 'Giombo', destanizados ou não, no armazenamento dos frutos sob atmosfera modificada e refrigerada.

\section{MATERIAL E MÉTODOS}

Frutos de caqui 'Giombo' foram adquiridos na Fazenda Sacramento Agropastoril Ltda., de Avaré (SP), localizada à latitude $23^{\circ} 05^{\prime} 56^{\prime}$ 'S, longitude 48 55'33"W e altitude de 780 metros, com precipitação anual de 1.500 a $1.700 \mathrm{~mm}^{2} \mathrm{ano}^{-1}$, temperatura anual entre $20^{\circ} \mathrm{C}$ e $24^{\circ} \mathrm{C}$ e solo classificado como Latossolo Roxo ( terra estruturada, terra roxa latossólica). Os frutos foram colhidos manualmente, no estádio 3 de maturação, fruto meio maduro e com aproximadamente $50 \%$ da coloração verde, sendo este o melhor período para a colheita dos frutos (PICANÇO, 2009). Para destanização, os frutos foram colocados em caixas plásticas e acondicionados em câmara a $25^{\circ} \mathrm{C}$ por 48 horas, e durante este período ficaram expostos ao vapor de álcool etílico na concentração de $6,6 \mathrm{~mL} \cdot \mathrm{kg}^{-1}$ fruto $(80 \mathrm{~mL} / 12 \mathrm{~kg})$.

Os frutos destanizados, ou não, foram imersos em água $(\mathrm{T} 1=$ controle $)$, ou em solução de cloreto de cálcio por 10 minutos. As concentrações avaliadas foram: $\mathrm{T} 2=0,5 \% \mathrm{CaCl}_{2} ; \mathrm{T} 3=1,0 \% \mathrm{CaCl}_{2} ; \mathrm{T} 4=2,0 \%$ $\mathrm{CaCl}_{2}$, e T5 $=3,0 \% \mathrm{CaCl}_{2}$. Os frutos foram acondicionados em bandejas de poliestireno expandido, com duas unidades, embalados com filme de policloreto de vinila $0,020 \mathrm{~mm}$ e armazenados sob refrigeração a $0 \pm 1^{\circ} \mathrm{C}$ ( $85 \pm 5 \%$ UR). Segundo Picanço (2009); esta é a temperatura mais indicada para o armazenamento dos frutos e umidade controlada (85-90\%) por 35 dias e analisados a cada 7 dias. Os frutos foram avaliados quanto à perda de massa, firmeza e atividade da poligalacturonase e da pectinametilesterase.

A perda de massa fresca foi obtida pela pesagem das embalagens em balança analítica, considerando a massa inicial de cada amostra, com os resultados expressos em percentagem.

A firmeza foi determinada com auxílio do Texturômetro (STEVENS - LFRA Texture Analyser) 
com penetração de $10 \mathrm{~mm}$, à velocidade de $2,0 \mathrm{~mm}$ $\mathrm{seg}^{-1}$, utilizando-se de ponteiro TA 9/1000. O valor obtido para se determinar a textura em grama15 força por centímetro quadrado $\left(\left(\mathrm{gf} / \mathrm{cm}^{2}\right)\right.$ é definido como a força máxima requerida para que uma parte do ponteiro penetre na polpa do produto.

A atividade da poligalacturonase $(\mathrm{PG})$ e a da pectinametilesterase (PME) foram respectivamente avaliadas pelo método proposto por Albersheim at al. (1974) e Ahmed \& Labavitch (1980).

Os resultados foram submetidos à análise de variância segundo esquema fatorial, e teste de Tukey para comparação múltipla entre as médias, ao nível de $5 \%$.

\section{RESULTADOS E DISCUSSÃO}

Não se observou ocorrência de interação dupla significativa entre os fatores (doses x tempo), mas foi observada interação entre os fatores isolados (Tabela 1). Os frutos destanizados, quando submetidos à aplicação de cloreto de cálcio a 1,0\% e $2,0 \%$, apresentaram as menores perdas de massa e, portanto, com o maior potencial de conservação que os submetidos a $0,5 \%$ de $\mathrm{CaCl}_{2}$.

Ao longo do armazenamento observou-se que a perda de massa acumulada nos frutos foi linear, com perda de massa, média, de $0,36 \%$ ao dia, que resultou em perda total de 1,80\% após 35 dias de armazenamento, que são semelhantes aos encontrados por Blum et al. (2008), ou seja, perda de massa de $0,34 \%$ ao dia nos caquis tratados com emulsão de cera de carnaúba.

Observou-se interação dupla entre os fatores estudados (doses $\mathrm{x}$ tempo), com perda de massa do caqui 'Giombo' não destanizado de $0,60 \%$ ao dia, em média, resultando em perda total de $2,99 \%$ no final do período (Tabela 2).Essas perdas não foram capazes de causar notáveis murchamento e/ou enrugamentos nos frutos, que pudessem comprometer sua qualidade. Entre os tratamentos, verifica-se que os frutos da testemunha apresentaram as menores perdas de massa.

A máxima perda de massa tolerada para o não aparecimento de murcha e/ou enrugamento da superfície oscila entre $5 \%$ e $10 \%$, para a maioria dos produtos hortícolas frescos (FINGER;VIERA, 2002), indicando que as perdas de massa do caqui 'Giombo', se encontram dentro de intervalo aceitável. O armazenamento refrigerado e a atmosfera modificada, criada nas embalagens, podem ter contribuído para este fato.

Não se observou interação dupla significativa entre os fatores estudados (doses $\mathrm{x}$ tempo) para a firmesa dos frutos (Tabelas 3 e 4), sendo que, para os frutos destanizados, ela não foi influenciada por nenhum dos tratamentos estudados durante o período de armazenamento refrigerado, com valores oscilando entre 580,8 - 690,4 gf/ $\mathrm{cm}^{-2}$ (Tabela 3). Para os frutos não destanizados, observou-se diferença estatística para os fatores isolados, sendo que, no decorrer das avaliações, houve decréscimo linear na firmeza dos frutos em todos os tratamentos (Tabela 4). A testemunha apresentou o maior valor médio de firmeza, diferenciando-se significativamente dos demais tratamentos.

Izumi e Watada (1994) e Antoniolli et al. (2003) também observaram que os tratamentos com $\mathrm{CaCl}_{2}(0,5 \%$ e $1,0 \%)$ não apresentaram efeito sobre a firmeza dos frutos. Este efeito pode ser atribuído à insuficiente absorção do cálcio pelo tecido, devido ao tempo de imersão, ou pela estrutura da polpa do fruto.

Verificou-se aumento na atividade da PME em todos os tratamentos, com interação dupla significativa entre os fatores estudados (doses x dias), tendo como exceção o $7^{\circ}$ dia de armazenamento para os frutos destanizados e do $14^{\circ}$ dia para os não destanizados, quando se observou decréscimo nos valores (Tabelas 5 e 6), o qual se ao estádio de maturação dos frutos e pelo efeito da amostragem para este método de análise que é destrutivo.

Verifica-se, de maneira geral, que a atividade da PME dos frutos aumentou até o $21^{\circ}$ dia para os frutos da testemunha, enquanto nos submetidos a $1,0 \%$ e $2,0 \%$ de $\mathrm{CaCl}_{2}$ este aumento foi verificado no $28^{\circ}$ dia, quando a atividade desta se reduziu significativamente (Tabela 5).

Nos frutos destanizados e submetidos a $0,5 \%$ e 3,0\% de $\mathrm{CaCl}_{2}$, o aumento da PME foi maior que nos demais tratamentos, no último dia de avaliação, enquanto nos frutos não destanizados, esse aumento também foi observado nas mesmas concentrações. Acréscimos na atividade da PME dos frutos, durante o período de armazenamento, também foram observados por Xisto et al.(2004) em goiabas cv. Pedro Sato submetidas ao tratamento hidrotérmico com cloreto de cálcio e armazenadas em condições ambientais.

Cheftel e Cheftel (1992) citam que a função da PME no processo de amaciamento dos frutos é desmetilar o $\mathrm{C}_{6}$ de cada unidade de protopectina, possibilitando o reconhecimento pela PG. Portanto, a atividade da $\mathrm{PME}$ deve preceder à atividade da $\mathrm{PG}$, no sentido de facilitar a atividade desta última. De acordo com esses autores, a PG teria maior afinidade pelo substrato linear, desesterificado, após a atuação da PME. Essa hipótese pode ser comprovada com os resultados deste experimento, em que a atividade da PME dos frutos destanizados se elevou no $14^{\circ}$ dia de armazenamento, enquanto a atividade da PG só 
mostrou aumento no $21^{\circ}$ dia (Tabela 7). Os frutos não destanizados (Tabela 8) apresentaram menor atividade que os destanizados.

A atividade da poligacturonase (PG) nos frutos não destanizados foi menor, com os maiores valores em 879,4 U.E. $\mathrm{min}^{-1} \cdot \mathrm{g}^{-1}$ de tecido fresco, com exceção da testemunha que apresentou 1.005,8 U.E. $\mathrm{min}^{-1} \cdot \mathrm{g}^{-1}$ de tecido fresco, quando comparado aos frutos destanizados (Tabelas 7 e 8).
Considerando-se a firmeza dos caquis 'Giombo', destanizados ou não, submetidos à aplicação de $\mathrm{CaCl}_{2}$ (Tabelas 3 e 4), correlacionou-se com a atividade das enzimas pectinolíticas (PME e PG), indicando que, quanto maior a atividade das enzimas citadas menor a firmeza dos frutos, confirmando a hipótese de que há uma ação conjunta destas enzimas na transformação das substâncias pécticas durante o amadurecimento do caqui.

TABELA 1 - Perda de massa em caqui 'Giombo', destanizado ou não, e submetido à aplicação de $\mathrm{CaCl}_{2}$ antes de serem armazenados a $0^{\circ} \mathrm{C}$ e $85 \%$ UR.

\begin{tabular}{ccccccc}
\hline \multirow{2}{*}{ Trat } & \multicolumn{5}{c}{ Dias de armazenamento } & \multirow{2}{*}{ Média } \\
\cline { 2 - 6 } & $\mathbf{7}$ & $\mathbf{1 4}$ & $\mathbf{2 1}$ & $\mathbf{2 8}$ & $\mathbf{3 5}$ & \\
\hline Test & $0,34 \pm 0,33$ & $0,77 \pm 0,31$ & $1,08 \pm 0,28$ & $1,36 \pm 0,25$ & $1,66 \pm 0,23$ & $1,05 \mathrm{ab} \pm 0,53$ \\
$0,5 \%$ & $0,30 \pm 0,15$ & $1,11 \pm 0,49$ & $1,45 \pm 0,57$ & $1,72 \pm 0,58$ & $2,05 \pm 0,59$ & $1,33 \mathrm{a} \pm 0,752$ \\
$1,0 \%$ & $0,13 \pm 0,01$ & $0,53 \pm 0,03$ & $0,93 \pm 0,08$ & $1,28 \pm 0,12$ & $1,66 \pm 0,14$ & $0,91 \mathrm{~b} \pm 0,56$ \\
$2,0 \%$ & $0,33 \pm 0,18$ & $0,70 \pm 0,18$ & $0,97 \pm 0,17$ & $1,28 \pm 0,18$ & $1,66 \pm 0,19$ & $0,98 \mathrm{~b} \pm 0,49$ \\
$3,0 \%$ & $0,40 \pm 0,40$ & $0,82 \pm 0,39$ & $1,16 \pm 0,38$ & $1,57 \pm 0,38$ & $2,02 \pm 0,37$ & $1,19 \mathrm{ab} \pm 0,67$ \\
\hline Média & $0,303 \mathrm{C} \pm 0,23$ & $0,789 \mathrm{~B} \pm 0,33$ & $1,123 \mathrm{~B} \pm 0,35$ & $1,446 \mathrm{~A} \pm 0,34$ & $1,811 \mathrm{~A} \pm 0,34$ & \\
\hline
\end{tabular}

Médias seguidas pela mesma letra, minúscula na coluna e maiúscula na linha, não diferem significativamente entre si, a $5 \%$ de probabilidade, pelo teste de Tukey.

TABELA 2 - Perda de massa em caqui 'Giombo', destanizado ou não, e submetido à aplicação de $\mathrm{CaCl}_{2}$ antes de serem armazenados a $0^{\circ} \mathrm{C}$ e $85 \pm 5 \%$ UR, por 35 dias.

\begin{tabular}{ccccccc}
\hline \multirow{2}{*}{ Trat } & \multicolumn{5}{c}{ Dias de armazenamento } & Média \\
\cline { 2 - 6 } & $\mathbf{7}$ & $\mathbf{1 4}$ & $\mathbf{2 1}$ & $\mathbf{2 8}$ & $\mathbf{3 5}$ & \\
\hline Test & $0,14 \mathrm{aE} \pm 0,04$ & $0,67 \mathrm{cD} \pm 0,05$ & $1,11 \mathrm{eC} \pm 0,04$ & $1,63 \mathrm{cB} \pm 0,18$ & $2,32 \mathrm{eA} \pm 0,19$ & $0,98 \pm 0,84$ \\
$0,5 \%$ & $0,14 \mathrm{aE} \pm 0,01$ & $0,79 \mathrm{cdD} \pm 0,02$ & $1,40 \mathrm{dC} \pm 0,04$ & $1,85 \mathrm{cB} \pm 0,13$ & $2,62 \mathrm{dA} \pm 0,13$ & $1,14 \pm 0,95$ \\
$1,0 \%$ & $0,14 \mathrm{aE} \pm 0,03$ & $1,03 \mathrm{abD} \pm 0,10$ & $1,84 \mathrm{abC} \pm 0,13$ & $2,89 \mathrm{aB} \pm 0,04$ & $3,80 \mathrm{a} A \pm 0,16$ & $1,65 \pm 1,39$ \\
$2,0 \%$ & $0,14 \mathrm{aE} \pm 0,01$ & $0,96 \mathrm{bcD} \pm 0,05$ & $1,77 \mathrm{bcC} \pm 0,10$ & $2,43 \mathrm{bB} \pm 0,18$ & $2,95 \mathrm{cA} \pm 0,15$ & $1,38 \pm 1,14$ \\
$3,0 \%$ & $0,14 \mathrm{aE} \pm 0,02$ & $1,26 \mathrm{aD} \pm 0,10$ & $2,08 \mathrm{aC} \pm 0,07$ & $2,83 \mathrm{aB} \pm 0,20$ & $3,24 \mathrm{bA} \pm 0,25$ & $1,63 \pm 1,23$ \\
\hline Média & $0,24 \pm 0,11$ & $0,94 \pm 0,22$ & $1,64 \pm 0,36$ & $2,33 \pm 0,55$ & $2,99 \pm 0,55$ & \\
\hline
\end{tabular}

Médias seguidas pela mesma letra, minúscula na coluna e maiúscula na linha, não diferem significativamente entre si, a 5\% de probabilidade, pelo teste de Tukey.

TABELA 3 - Firmeza $\left(\mathrm{gf} \mathrm{cm}^{-2}\right)$ de caqui ‘Giombo'destanizado e submetido à aplicação de $\mathrm{CaCl}_{2}$, armazenados a $0 \pm 1^{\circ} \mathrm{C}$ e $85 \pm 5 \%$ UR, por 35 dias.

\begin{tabular}{|c|c|c|c|c|c|c|c|}
\hline \multirow{2}{*}{ Trat } & \multicolumn{6}{|c|}{ Dias de armazenamento } & \multirow[t]{2}{*}{ Média } \\
\hline & $\mathbf{0}$ & 7 & 14 & 21 & 28 & 35 & \\
\hline Test & $670,8 \pm 47$ & $706,7 \pm 29$ & $627,3 \pm 105$ & $724,3 \pm 69$ & $603,3 \pm 108$ & $566,8 \pm 90$ & $649,9 \pm 88$ \\
\hline $0,5 \%$ & $670,8 \pm 47$ & $554,8 \pm 43$ & $756,2 \pm 88$ & $662,7 \pm 25$ & $568,5 \pm 60$ & $616,7 \pm 217$ & $638,3 \pm 1112$ \\
\hline $1,0 \%$ & $670,8 \pm 47$ & $652,3 \pm 103$ & $720,7 \pm 97$ & $610,2 \pm 20$ & $605,8 \pm 60$ & $703,8 \pm 76$ & $660,6 \pm 76$ \\
\hline $2,0 \%$ & $670,8 \pm 47$ & $641 \pm 54$ & $725,5 \pm 57$ & $624,8 \pm 63$ & $560,8 \pm 169$ & $552,3 \pm 89$ & $629,2 \pm 98$ \\
\hline $3,0 \%$ & $670,8 \pm 47$ & $734,8 \pm 81$ & $622,3 \pm 65$ & $682,8 \pm 99$ & $565,7 \pm 120$ & $635,2 \pm 145$ & $651,9 \pm 99$ \\
\hline Média & $670,8 \mathrm{AB} \pm 47$ & $657,9 \mathrm{AB} \pm 86$ & $690,4 \mathrm{~A} \pm 91$ & $661,0 \mathrm{AB} \pm 67$ & $580,8 \mathrm{~B} \pm 96$ & $615 \mathrm{AB} \pm 126$ & \\
\hline
\end{tabular}

Médias seguidas pela mesma letra, minúscula na coluna e maiúscula na linha, não diferem significativamente entre si, a 5\% de probabilidade, pelo teste de Tukey. 
TABELA 4 - Firmeza $\left(\mathrm{gf} \mathrm{cm}^{-2}\right)$ de caqui ‘Giombo'não destanizado e submetido à aplicação de $\mathrm{CaCl}_{2}$, armazenados a $0 \pm 1^{\circ} \mathrm{C}$ e $85 \pm 5 \%$ UR, por 35 dias.

\begin{tabular}{|c|c|c|c|c|c|c|c|}
\hline \multirow{2}{*}{ Trat } & \multicolumn{6}{|c|}{ Dias de armazenamento } & \multirow[t]{2}{*}{ Média } \\
\hline & $\mathbf{0}$ & 7 & 14 & 21 & 28 & 35 & \\
\hline Test & $830,6 \pm 95$ & $755,5 \pm 82$ & $740,3 \pm 77$ & $635,2 \pm 99$ & $633,5 \pm 123$ & $495,3 \pm 151$ & $684,3 a \pm 147$ \\
\hline $0,5 \%$ & $830,6 \pm 95$ & $663,7 \pm 73$ & $762,7 \pm 60$ & $508,3 \pm 155$ & $278,3 \pm 75$ & $218,5 \pm 172$ & $514,7 \mathrm{~b} \pm 233$ \\
\hline $1,0 \%$ & $830,6 \pm 95$ & $681,7 \pm 61$ & $657,7 \pm 99$ & $614 \pm 308$ & $303,8 \pm 59$ & $198 \pm 109$ & $518,7 \mathrm{~b} \pm 237$ \\
\hline $2,0 \%$ & $830,6 \pm 95$ & $739,8 \pm 50$ & $738,5 \pm 36$ & $483,3 \pm 286$ & $322,3 \pm 267$ & $99,2 \pm 74$ & $506,7 \mathrm{~b} \pm 283$ \\
\hline $3,0 \%$ & $830,6 \pm 95$ & $701,5 \pm 50$ & $532,5 \pm 297$ & $401 \pm 261$ & $459,8 \pm 106$ & $385,8 \pm 88$ & $522,9 b \pm 197$ \\
\hline Média & $830,6 \mathrm{~A} \pm 95$ & $708,4 \mathrm{~A} \pm 65$ & $686,3 \mathrm{~A} \pm 153$ & $528,36 \mathrm{AB} \pm 250$ & $399,54 \mathrm{~B} \pm 204$ & $291,32 \mathrm{~B} \pm 181$ & \\
\hline
\end{tabular}

Médias seguidas pela mesma letra, minúscula na coluna e maiúscula na linha, não diferem significativamente entre si, a 5\% de probabilidade, pelo teste de Tukey.

TABELA 5 - Pectinametilesterase (UE. $\mathrm{min}^{-1} \cdot \mathrm{g}^{-1}$ de tecido fresco) em caqui 'Giombo'destanizado e submetido à aplicação de $\mathrm{CaCl}_{2}$, armazenados a $0 \pm 1^{\circ} \mathrm{C}$ e $85 \pm 5 \% \mathrm{UR}$, por 35 dias.

\begin{tabular}{rcccccc}
\hline \multirow{2}{*}{ Trat } & \multicolumn{6}{c}{ Dias de armazenamento } \\
\cline { 2 - 7 } & $\mathbf{0}$ & $\mathbf{7}$ & $\mathbf{1 4}$ & $\mathbf{2 1}$ & $\mathbf{2 8}$ & $\mathbf{3 5}$ \\
\hline Test & $1343,4 \mathrm{aD}$ & $838,7 \mathrm{bcE}$ & $2524,5 \mathrm{bB}$ & $3368,4 \mathrm{aA}$ & $2648,2 \mathrm{cB}$ & $1626,9 \mathrm{cC}$ \\
$\mathbf{0 , 5 \%}$ & $1343,4 \mathrm{aE}$ & $646,6 \mathrm{cF}$ & $2029,9 \mathrm{cD}$ & $2392,8 \mathrm{bC}$ & $3120,8 \mathrm{bB}$ & $5709,5 \mathrm{aA}$ \\
$\mathbf{1 , 0 \%}$ & $1343,4 \mathrm{aB}$ & $987,6 \mathrm{bcC}$ & $818,4 \mathrm{eD}$ & $1503,8 \mathrm{~dB}$ & $3296,2 \mathrm{bA}$ & $1482,6 \mathrm{cB}$ \\
$\mathbf{2 , 0 \%}$ & $1343,4 \mathrm{aE}$ & $1264,7 \mathrm{aE}$ & $2886,3 \mathrm{aC}$ & $1828,9 \mathrm{cD}$ & $3746,9 \mathrm{aA}$ & $3108,9 \mathrm{bB}$ \\
$\mathbf{3 , 0 \%}$ & $1343,4 \mathrm{aC}$ & $841,0 \mathrm{bcE}$ & $1110,8 \mathrm{dC}$ & $1470,2 \mathrm{dC}$ & $1909,7 \mathrm{dD}$ & $5887,0 \mathrm{aA}$ \\
\hline
\end{tabular}

Médias seguidas pela mesma letra, minúscula na coluna e maiúscula na linha, não diferem significativamente entre si, a $5 \%$ de probabilidade, pelo teste de Tukey.

TABELA 6 - Pectinametilesterase (UE. $\mathrm{min}^{-1} \cdot \mathrm{g}^{-1}$ de tecido fresco) em caqui 'Giombo'não destanizado e submetido à aplicação de $\mathrm{CaCl}_{2}$, armazenados a $0 \pm 1^{\circ} \mathrm{C}$ e $85 \pm 5 \%$ UR, por 35 dias.

\begin{tabular}{ccccccc}
\hline \multirow{2}{*}{ Trat } & \multicolumn{7}{c}{ Dias de armazenamento } \\
\cline { 2 - 7 } & $\mathbf{0}$ & $\mathbf{7}$ & $\mathbf{1 4}$ & $\mathbf{2 1}$ & $\mathbf{2 8}$ & $\mathbf{3 5}$ \\
\hline Test & $1339,8 \mathrm{aB}$ & $1151,5 \mathrm{cC}$ & $957,4 \mathrm{cC}$ & $769,0 \mathrm{cD}$ & $2486,4 \mathrm{dAB}$ & $3211,1 \mathrm{cA}$ \\
$\mathbf{0 , 5 \%}$ & $1339,8 \mathrm{aB}$ & $2084,9 \mathrm{aB}$ & $392,19 \mathrm{dD}$ & $910,0 \mathrm{cC}$ & $11869,2 \mathrm{aA}$ & $11281,0 \mathrm{aA}$ \\
$\mathbf{1 , 0 \%}$ & $1339,8 \mathrm{aB}$ & $1850,5 \mathrm{aB}$ & $2420,3 \mathrm{bB}$ & $1034,8 \mathrm{bB}$ & $3450,3 \mathrm{cB}$ & $10433,6 \mathrm{aA}$ \\
$\mathbf{2 , 0 \%}$ & $1339,8 \mathrm{aB}$ & $1690,6 \mathrm{bB}$ & $1069,36 \mathrm{cC}$ & $2408,3 \mathrm{aB}$ & $7393,0 \mathrm{bA}$ & $8471,9 \mathrm{bA}$ \\
$\mathbf{3 , 0 \%}$ & $1339,8 \mathrm{aB}$ & $1276,9 \mathrm{cB}$ & $4695,5 \mathrm{aB}$ & $787,1 \mathrm{bC}$ & $10433,6 \mathrm{aA}$ & $11000,7 \mathrm{aA}$ \\
\hline
\end{tabular}

Médias seguidas pela mesma letra, minúscula na coluna e maiúscula na linha, não diferem significativamente entre si, a 5\% de probabilidade, pelo teste de Tukey.

TABELA 7 - Poligalacturonase (UE. $\mathrm{min}^{-1} \cdot \mathrm{g}^{-1}$ de tecido fresco) em caqui ‘Giombo'destanizado e submetido à aplicação de $\mathrm{CaCl}_{2}$, armazenados a $0 \pm 1^{\circ} \mathrm{C}$ e $85 \pm 5 \%$ UR, por 35 dias.

\begin{tabular}{ccccccc}
\hline \multirow{2}{*}{ Trat } & \multicolumn{7}{c}{ Dias de armazenamento } \\
\cline { 2 - 7 } & $\mathbf{0}$ & $\mathbf{7}$ & $\mathbf{1 4}$ & $\mathbf{2 1}$ & $\mathbf{2 8}$ & $\mathbf{3 5}$ \\
\hline Test & $889 \mathrm{aB} \pm 143$ & $464,2 \mathrm{abC} \pm 56$ & $520,8 \mathrm{aC} \pm 40$ & $793,3 \mathrm{bB} \pm 134$ & $1494,6 \mathrm{aA} \pm 81$ & $1283,0 \mathrm{aA} \pm 47$ \\
$\mathbf{0 , 5 \%}$ & $889 \mathrm{aA} \pm 143$ & $484,8 \mathrm{aB} \pm 59$ & $327,1 \mathrm{aB} \pm 61$ & $923,7 \mathrm{abA} \pm 13$ & $1052,5 \mathrm{bA} \pm 187$ & $1044,8 \mathrm{bA} \pm 46$ \\
$\mathbf{1 , 0 \%}$ & $889 \mathrm{aB} 143$ & $262,7 \mathrm{bC} \pm 132$ & $535,9 \mathrm{aC} \pm 109$ & $1011,9 \mathrm{aA} \pm 45$ & $705,2 \mathrm{cBC} \pm 167$ & $625,2 \mathrm{c} \pm 57$ \\
$\mathbf{2 , 0 \%}$ & $889 \mathrm{aA} \pm 143$ & $456,3 \mathrm{abB} \pm 57$ & $530,1 \mathrm{aB} \pm 97$ & $1051,1 \mathrm{aA} \pm 26$ & $1106,8 \mathrm{bA} \pm 64$ & $1051,6 \mathrm{bA} \pm 24$ \\
$\mathbf{3 , 0 \%}$ & $889 \mathrm{aA} \pm 143$ & $483,2 \mathrm{aB} \pm 56$ & $540,1 \mathrm{aB} \pm 95$ & $1040,1 \mathrm{aA} \pm 29$ & $1108,5 \mathrm{bA} \pm 64$ & $1059,6 \mathrm{bA} \pm 25$ \\
\hline
\end{tabular}

Médias seguidas pela mesma letra, minúscula na coluna e maiúscula na linha, não diferem significativamente entre si, a 5\% de probabilidade, pelo teste de Tukey. 
TABELA 8. Poligalacturonase (UE. $\mathrm{min}^{-1} \cdot \mathrm{g}^{-1}$ de tecido fresco) em caqui 'Giombo'não destanizado e submetido à aplicação de $\mathrm{CaCl}_{2}$, armazenados a $0 \pm 1^{\circ} \mathrm{C}$ e $85 \pm 5 \%$ UR, por 35 dias.

\begin{tabular}{ccccccc}
\hline \multirow{2}{*}{ Trat } & \multicolumn{5}{c}{ Dias de armazenamento } \\
\cline { 2 - 7 } & $\mathbf{0}$ & $\mathbf{7}$ & $\mathbf{1 4}$ & $\mathbf{2 1}$ & $\mathbf{2 8}$ & $\mathbf{3 5}$ \\
\hline Test & $211,5 \mathrm{aE} \pm 83$ & $1005,8 \mathrm{a} \mathrm{A} \pm 9$ & $501,8 \mathrm{aCD} \pm 54$ & $732,2 \mathrm{aB} \pm 141$ & $670,0 \mathrm{aBC} \pm 61$ & $426,8 \mathrm{bD} \pm 93$ \\
$\mathbf{0 , 5 \%}$ & $211,5 \mathrm{aB} \pm 83$ & $247,1 \mathrm{cB} \pm 68$ & $192,1 \mathrm{bcB} \pm 51$ & $489,9 \mathrm{bA} \pm 135$ & $561,1 \mathrm{aA} \pm 52$ & $442,7 \mathrm{bA} \pm 10$ \\
$\mathbf{1 , 0 \%}$ & $211,5 \mathrm{aB} \pm 83$ & $836,4 \mathrm{bA} \pm 31$ & $116,5 \mathrm{cB} \pm 51$ & $114,7 \mathrm{cB} \pm 47$ & $722,4 \mathrm{aA} \pm 36$ & $879,4 \mathrm{aA} \pm 32$ \\
$\mathbf{2 , 0 \%}$ & $211,5 \mathrm{aC} \pm 83$ & $337,2 \mathrm{cB} \pm 33$ & $346,3 \mathrm{abB} \pm 79$ & $73,7 \mathrm{cC} \pm 65$ & $268,0 \mathrm{aB} \pm 60$ & $552,1 \mathrm{bA} \pm 35$ \\
$\mathbf{3 , 0 \%}$ & $211,5 \mathrm{aC} \pm 83$ & $186,7 \mathrm{cC} \pm 36$ & $208,5 \mathrm{bcC} \pm 99$ & $442,4 \mathrm{bA} \pm 97$ & $384,4 \mathrm{bAB} \pm 46$ & $237,3 \mathrm{cC} \pm 37$ \\
\hline
\end{tabular}

Médias seguidas pela mesma letra, minúscula na coluna e maiúscula na linha, não diferem significativamente entre si, a $5 \%$ de probabilidade, pelo teste de Tukey.

\section{CONCLUSÃO}

A aplicação do cloreto de cálcio não apresentou incrementos positivos na manutenção da qualidade pós-colheita do caqui 'Giombo'.

\section{AGRADECIMENTOS}

À FAPESP e ao Conselho Nacional de Desenvolvimento Científico e Tecnológico.

\section{REFERÊNCIAS}

ANTONIOLLI, L. R.; BENEDETTI, B. C.; SOUZA, FILHO, M.de S. Efeito do cloreto de cálcio na qualidade de abacaxi 'Pérola' minimamente processado. Pesquisa Agropecuária Brasileira, Brasília, v. 38, n. 9, p. 1105-1110, Brasília, 2003.

ANTONIOLLI, L. R.; CAMARGO e CASTRO, P. R.; KLUGE, R. A.; SCARPARE, F. J. A. Remoção da adstringência de frutos de caquizeiro 'Giombo' sob diferentes períodos de exposição ao vapor de álcool etílico. Pesquisa Agropecuária Brasileira, Brasília, v. 35, n. 10, p. 2083-2091, 2000.

AHMED, E. A.; LABAVITCH, J. M. Cell wall metabolism in ripening. I cell wall changes in ripening "Bartlett" pears. Plant Physiology, Rockville, v.65, p. 1009-1013, 1980.

ALBERSHEIM, P.; NEVINS, D. J.; ENGLISH, P. D.; KARR, A. A method for the analysis of sugars in plant cell wall polysaccharides by gas-liquid chromatography. Carbohydrate Research, Amsterdam, v.5, p.340-345, 1967.
BLUM, J.; HOFFMANN, F. B.; AYUB, R. A.; JUNG, D. L.; MALGARIM, M. B. Uso de cera na conservação pós-colheita do caqui cv. Giombo. Revista Brasileira de Fruticultura, Jaboticabal, v. 30, n. 3, p.830-833, 2008.

BRACKMANN, A. Capa: a produção, o consumo e a qualidade do caqui no Brasil. Revista Brasileira de Fruticultura, Jaboticabal, v. 25, n. 1, 2003. Disponível em: < http://www.scielo.br/pdf/rbf/v25n1/ a01v25n1.pdf > . Acesso em: 10 maio 2011.

CAMPODALL'ORTO, F. A.; OJIMA, M.; BARBOSA, W.; ZULLO, M. A. T. Novo processo de avaliação da adstringência dos frutos no melhoramento do caquizeiro. Bragantia, Campinas, v.55, n.2, p.237-243, 1996.

CHEFTEL, J.C.; CHEFTEL, H. Métodos de conservación. In: Introdución a la bioquimica y tecnologia de los alimentos. Zaragoza, Acribia, 1992. p.173-300.

CHITARRA, M. I. F.; CHITARRA, A. B. Pós-colheita de frutos e hortaliças: fisiologia e manuseio. Lavras: Ed UFLA, 2005. 785 p.

DANIELI, R.; GIRARDI, C.L.; PARUSSOLO, A.; FERRI, V.C.; ROMBALDI, C.V. Efeito da aplicação de ácido giberélico e cloreto de cálcio no retardamento da colheita e na conservabilidade de caqui Fuyu. Revista Brasileira de Fruticultura, Jaboticabal, v. 24, n. 1, p. 44-48, 2002.

DONAZZOLO, J. ; BRACKMANN, A. Efeito do $\mathrm{CO} 2 \mathrm{em}$ atmosfera controlada na qualidade de caqui (diospyros kaki, 1.) Cv. Fuyu. Revista Brasileira Agrociência, Pelotas, v.8, n.3, p.241-245, 2002. 
FINGER, F. L.; VIEIRA, G. Controle da perda pós-colheita de água em produtos hortícolas. Viçosa: UFV, 2002. 29 p.

EDAGI, F.K.; KLUGE, R. A. Remoção de adstringência de caqui: um enfoque bioquímico, fisiológico e tecnológico. Ciência Rural, Santa Maria, v.39, n.2, p.585-594, 2009.

GLENN, G.M.; REDDY, A.S.N.; POOVAIAH, B.W. Effect of calcium cell wall structure protein phodphorilation and protein profile in senecing apples. Plant and Cell Physiology, Kamikyo-Ku, v.29, n.4, p.565-572, 1988.

IZUMI, H.; WATADA, A. E. Calcium treatments affect storage quality of shredded carrots. Journal of Food Quality, Trumbull, v. 59, n. 1, p. 106-109, 1994.

PEREZ, A.; BEN-ARIE, R.; DINNOR, A.; GENIZI, A.; PRUSKY,D. Prevention of black spot disease in persimmon fruit by gibberellic acid and iprodione treatments. Phytopathology, St. Paul,v. 85, n.2, p.221-225, 1995.

PENTEADO, S.R. Cultura do caquizeiro. In: PENTEADO, S.R. (Ed.). Fruticultura de clima temperado em São Paulo. Campinas: Fundação Cargill, 1986. cap.8, p.157-173.

PICANÇO, N. F. M. Qualidade de caqui armazenado sob refrigeração: estádios de maturação, destanização e irradiação ionozante. 2009. 125f. Tese (Doutorado em Agronomia) - Faculdade de Ciências Agronômicas, Universidade Estadual Paulista, Botucatu, 2009.
POOVAIAH, B. W. Role of calcium in prolonging storage life of fruyt and vegetables. Food Technology, Chicago, v.16, p.86-89,1986.

SCALON, S. P. Q.; BITTENCOURT, A. L.; CHITARRA, A. B.; CHITARRA, M. I. F. A evolução da qualidade e da vida útil de morangos (Fragraria ananassa, Duch.) submetidos à aplicação pós-colheita de $\mathrm{CaCl}_{2}$ armazenados sob atmosfera modificada e à temperatura ambiente. Ciência e Tecnologia de Alimentos, Campinas, v.16, n.1, p.83-87, 1996.

SIMÃO, S. Tratado de fruticultura. Piracicaba: FEALQ, 1998. 760p.

VASCONCELOS, A.R.D. Utilização de cloreto de cálcio e atmosfera modifcada na conservação de caqui cv. Fuyu. 2000. 85 f. Dissertação (Mestrado em Ciências dos Alimentos) - Universidade Federal de Lavras, Lavras, 2000.

VIDRIH, R.; SIMCIC, M.; HRIBAR, J. Storing of persimmon fruit under controlled atmosphere conditons. In: INTERNATIONAL HORTICULTURAL CONGRESS, 23., 1990, Firenze. Abstracts... Firenze : ISHS, 1990. v.2, p.3312.

WRIGHT, K. P.; KADER, A. A. Effect of slicing and controlled atmosphere storage on the ascorbate content and quality of strawberries and persimmons. Postharvest Biology and Technology, Amsterdam, v. 10, n. 1, p. 39-48, 1997.

XISTO, A. L. R. P.; ABREU, C. M. P.; CORRÊA, A. D.; SANTOS, C. D. Textura de goiabas "pedro sato" submetidas à aplicação de cloreto de cálcio. Ciência e Agrotecnologia, Lavras, v.28, n. 1, p.113-118, 2004. 